\title{
Oxygen - Mitochondrial fuel as a missing link in depressive pathophysiology
}

R. Nehir Mavioglu*, Matthias Mack*, Alexander Behnke, Iris-Tatjana Kolassa

Department of Clinical and Biological Psychology, Ulm University, Ulm, Germany

* Equal contribution. Correspondence to this work can be addressed to either of the authors by email: nehir.mavioglu@uni-ulm.de (RNM), matthias.mack@uni-ulm.de (MM)

ORCID IDs: 0000-0003-4154-6475 (RNM), 0000-0001-7937-079X (MM), 0000-0002-41289627 (AB), 0000-0001-7847-1847 (ITK)

\section{Acknowledgements}

This work was supported by the European Research Council (ERC) under the European Union's Horizon 2020 research and innovation program (Grant agreement No. 865077 awarded to ITK). The authors report no conflicts of interest. We thank Madlaina Kaupp and Suchithra Varadarajan for their comments for an earlier version of this manuscript.

\section{Author Contributions}

MM and RNM conceptualized the model, with critical contribution from AB and ITK. RNM and $\mathrm{MM}$ reviewed the literature and wrote the manuscript. $\mathrm{AB}$ and ITK edited and revised the manuscript. 


\begin{abstract}
Major depressive disorder (MDD) causes enormous individual suffering and socioeconomic costs. Biochemical mechanisms leading to MDD are poorly understood and therapy success is not satisfactory. At present, there is evidence of low-grade inflammation, oxidative stress, and most interestingly, a disturbed energy metabolism in MDD and other mental disorders. Mitochondria play a central part in energy production and stress signaling. Mitochondrial electron transport chain uses molecular oxygen $\left(\mathrm{O}_{2}\right)$ as final electron acceptor during adenosine triphosphate production attributing a crucial role to an intact $\mathrm{O}_{2}$ supply. Adaptation to altered $\mathrm{O}_{2}$ availability by the highly conserved hypoxic response is essential for maintaining allostasis. Previous research confirmed the role of $\mathrm{O}_{2}$ metabolism in the pathophysiology of MDD. In this perspective article, we compile the evidence linking $\mathrm{O}_{2}$ transport, $\mathrm{O}_{2}$ homeostasis, and mitochondrial energy metabolism to MDD. Furthermore, we hypothesize that inflammation and oxidative stress-related alterations in $\mathrm{O}_{2}$ transport might lead to a hypoxic response, which explains changes in $\mathrm{O}_{2}$ homeostasis and energy metabolism in MDD. Our forthcoming studies will investigate the interplay between energy metabolism and $\mathrm{O}_{2}$ homeostasis in MDD that aim to improve the overall understanding of the pathophysiology of MDD and to guide medical and psychological diagnostics towards a holistic strategy.
\end{abstract}




\section{Introduction}

Prevalence of major depressive disorder (MDD) is escalating, and it is a leading cause of disability and socioeconomic burden worldwide [1]. Yet, the pathophysiology of MDD is still not clear. Success of selective serotonin reuptake inhibitors in animal models led researchers to identify MDD as a lack of monoaminergic neurotransmitter availability in the brain [2, 3]. However, mixed success rate and relapses after remission indicate that monoaminergic antidepressants do not seem to sustainably cure the disease $[4,5]$. Finding better treatments depends on a more profound understanding of the disorder's biological underpinnings. Unfortunately, the current understanding of the pathophysiology of MDD is not sufficient to prompt therapeutic applications.

Recent transdisciplinary research has established mitochondrial functioning as an element in the pathophysiology of MDD and confirmed various physiological aberrations, including reduced mitochondrial energy production in immune cells, blood platelets, and muscle cells [68] as well as reduced energy production and adenosine triphosphate (ATP) shortage in the brain of MDD patients $[9,10]$, indicating MDD as a chronic state of systemic energy deficiency. Reduced cellular energy production limits the functionality of cells in depressed patients, leading to the characteristic findings in MDD, namely, lack of energy, fatigue, difficulties in concentration, memory consolidation, and emotion regulation problems as well as dysregulated inflammatory processes $[6,7,11]$. However, the physiological mechanisms underlying the altered mitochondrial function in MDD is unclear.

In this article, we propose a novel model of MDD as a hypoxic state, which could explain the dysregulation of the energy metabolism in the disease. For this purpose, we reviewed previous research about relevant processes that are associated with hypoxic response, i.e. oxygen $\left(\mathrm{O}_{2}\right)$ transport and homeostasis, and their role in cellular energy production. We propose that inflammation- and oxidative stress-related alterations in $\mathrm{O}_{2}$ transport and utilization result in a 
low-grade hypoxic state that might affect mitochondrial functioning in MDD. After a short summary of the energy production and related processes, evidence of a disturbed $\mathrm{O}_{2}$ transport in MDD is presented. Afterwards, molecular adaptation processes regulating $\mathrm{O}_{2}$ homeostasis upon hypoxic conditions and MDD will be described and specified in the context of mitochondrial functioning. Finally, main findings are recapitulated and integrated into our novel model of MDD pathophysiology.

\section{Cellular energy production and oxidative stress}

Biological energy is provided in cells consecutively by utilization of carbohydrates, production of electron carriers, establishment of a proton gradient, and final synthesis of ATP. Detailed information about the biological processes that are discussed in this paper can be found in Table 1. Briefly, carbohydrates are used during glycolysis, pyruvate oxidation, and citric acid cycle to provide the reduction equivalent nicotinamide adenine dinucleotide (NADH) [12]. In the subsequent oxidative phosphorylation (OXPHOS), electrons provided from NADH are passed across the mitochondrial electron transport chain (ETC), where $\mathrm{O}_{2}$ serves as the final electron acceptor, to pump protons out of the inner membrane. The resulting proton gradient is used to synthesize ATP, which is essential for all kinds of biochemical processes in living organisms [13]. However, due to disturbances or adaptive reprogramming of OXPHOS, excessive amounts of reactive oxygen species (ROS) can be produced. The imbalance between ROS and antioxidants is termed as oxidative stress. It is an intrinsic cellular demand to maintain ATP production and ROS formation at defined levels. As $\mathrm{O}_{2}$ is crucial to OXPHOS, it is vital to any cell to maintain adequate $\mathrm{O}_{2}$ supply, regulate its consumption, and adapt to altered $\mathrm{O}_{2}$ availability. 


\section{MDD as a low-grade hypoxic state: Disturbances in oxygen availability and transport}

This section focuses on the mechanisms and elements of $\mathrm{O}_{2}$ transport as well as their alterations in MDD and other mental disorders. Lower $\mathrm{O}_{2}$ levels in the tissue due to alterations in $\mathrm{O}_{2}$ transport and utilization might trigger a hypoxic response, which affects mitochondrial functioning and $\mathrm{O}_{2}$ homeostasis.

After being inhaled into the lungs, driven by a partial pressure gradient, $\mathrm{O}_{2}$ passively diffuses across the blood-air barrier and passes through the membrane of erythrocytes where it binds to hemoglobin. Hemoglobin consists of four globular protein subunits, each containing a central iron atom $\left(\mathrm{Fe}^{2+}\right)$ that is reversibly oxidized to $\mathrm{Fe}^{3+}$ with $\mathrm{O}_{2}$ binding. With this conformation, one hemoglobin molecule can bind a maximum of four $\mathrm{O}_{2}$ molecules. After binding to hemoglobin, $\mathrm{O}_{2}$ is distributed across the body via blood circulation. Where needed in tissues, $\mathrm{O}_{2}$ passively diffuses from blood to cells, and subsequently, into mitochondria to take role in ETC [14].

Particularly, hemoglobin's affinity to $\mathrm{O}_{2}$ in pulmonary and systemic capillaries is what brings $\mathrm{O}_{2}$ to the circulation, and releases it from the circulation. It is regulated in an "oxyhemoglobin equilibrium", which depends on the oxygen dissociation curve (ODC). ODC depicts the association between partial $\mathrm{O}_{2}$ pressure $\left(p \mathrm{O}_{2}\right)$ and $\mathrm{O}_{2}$ saturation in hemoglobin. It has a sigmoidal shape, meaning the binding of the first $\mathrm{O}_{2}$ to $\mathrm{Fe}^{2+}$ bolsters the second $\mathrm{O}_{2}$ binding, and as the number of $\mathrm{O}_{2}$ molecules bound to hemoglobin increases, more $p \mathrm{O}_{2}$ is required for additional $\mathrm{O}_{2}$ binding to hemoglobin [14]. The process is the opposite for unbinding. ODC is influenced by core physiological factors, namely body temperature, carbon dioxide concentration $\left(\mathrm{CO}_{2}\right), \mathrm{pH}$-levels, and 2,3-diphospho-glycerate (2,3-DPG) concentration. Increasing body temperature, $p \mathrm{CO}_{2}$, and 2,3-DPG, and decreasing $\mathrm{pH}$ result in a right shift in the ODC, meaning more $p \mathrm{O}_{2}$ is necessary to saturate hemoglobin, leading to decreased $\mathrm{O}_{2}$ hemoglobin affinity [15]. 
Factors that may cause a shift in ODC are found to be altered in MDD and other mental disorders. In particular, increased body or brain temperature was shown in individuals with MDD or schizophrenia, respectively $[16,17]$. Decreased brain $\mathrm{p} H$ was reported to be common in schizophrenia, bipolar disorder, and autism spectrum disorder [18], while higher venous blood $\mathrm{pH}$ was found in MDD patients [19]. In individuals with Alzheimer's disease and nonAlzheimer dementia, lower venous erythrocyte 2,3-DPG levels were found compared to controls [20]. These findings might indicate less affinity of hemoglobin to $\mathrm{O}_{2}$ in $\mathrm{MDD}$ and other mental disorders.

As suggested before, the central transition element of hemoglobin is iron. Thus, the iron metabolism and its highly conserved regulation are crucial for the $\mathrm{O}_{2}$ supply system as well as for the aerobic energy production. Studies reported associations between MDD risk and alterations in the iron metabolism, i.e., decreased ferritin, transferrin, hemoglobin, and erythrocyte counts [21-24]. Similarly, individuals with MDD show lower serum iron levels than controls [25]. However, other studies reported no association between MDD and serum iron, ferritin, and hemoglobin levels [26, 27]. Therefore, certain alterations in iron metabolism might be only relevant in certain subgroups of MDD. On the other hand, alterations in the iron regulation, rather than a huge effect in the steady-state level of iron parameters might be more likely in MDD. This hypothesis is supported by previous findings: While iron levels appear to be reduced in the blood of MDD patients, iron seems to accumulate in their brain, depicting a dysregulation in iron metabolism in MDD [28]. Moreover, increased levels of hepcidin were found in MDD patients with brain iron load [29]. Noteworthy, in order to restore and maintain $\mathrm{O}_{2}$ supply, hepcidin is induced via the influence of erythropoietic activity, hypoxia, and inflammation [30]. The important role of hepcidin was previously shown in a chronic mild stress-induced MDD model in rats, reporting increased iron and hepcidin mRNA levels in the hippocampi of stressed animals [31]. Therefore, compensatory alterations in hepcidin- 
dependent iron regulation in MDD might be a more reliable indicator of iron metabolism status compared to steady-state iron parameters.

Increased MDD prevalence was observed in patients displaying dysfunctions in $\mathrm{O}_{2}$ transport, such as iron-deficiency anemia [32] and sickle cell anemia [33]. Diseases that prevent sufficient air inhalation such as chronic obstructive pulmonary disease [34], asthma [35], and COVID-19 [36] have also been associated with higher MDD risk, compared to general population. Higher MDD rates were also found in people with chronic hypoxic conditions such as coronary heart disease and stroke [37].

Environmental factors like air pollution and altitude are known to reduce $\mathrm{O}_{2}$ availability and $\mathrm{O}_{2}$ saturation in humans, and lead to psychopathology. Accordingly, exposure to traffic-related air pollution evoked depressive symptoms in children [38], and air pollution was linked to a higher risk for suicide [39]. Similarly, a positive association between altitude and suicidal risk was observed [40]. Another study reported that students moving from a low altitude to a high altitude developed more depressive and anxiety symptoms compared to a control group that remained at low altitude [41]. These findings led to the interpretation that conditions which limit the $\mathrm{O}_{2}$ availability such as altitude and asthma might create a mild hypoxic state in individuals, resulting in mood disorders. Researchers speculated that hypoxic response can decrease serotonin synthesis [42], increase inflammatory response [43], or affect brain bioenergetics [44] and thus lead to suicide and MDD.

The studies mentioned above point towards an association of MDD and a disturbed $\mathrm{O}_{2}$ transport as well as decreased cellular $\mathrm{O}_{2}$ availability. Indeed, a case-control study performing venous blood gas analysis reported higher venous $p \mathrm{O}_{2}$ along with lower venous $p \mathrm{CO}_{2}$ in $\mathrm{MDD}$ patients compared to controls, which was interpreted as tissue hypoxia. A positive correlation between venous $p \mathrm{O}_{2}$ and depressive symptoms was also observed, exhibiting a reduced $\mathrm{O}_{2}$ utilization in MDD [19]. Moreover, compared to controls, less $\mathrm{O}_{2}$-saturated hemoglobin was observed in the 
frontotemporal cortex of MDD patients during a verbal task [45, 46], highlighting the relevance of $\mathrm{O}_{2}$ insufficiency in cognitive symptoms of MDD.

Altogether, studies provide evidence for $\mathrm{O}_{2}$ insufficiency in MDD in conditions both with and without a scarce of $\mathrm{O}_{2}$, suggesting relative tissue hypoxia as one contributing factor in the pathophysiology of MDD. Hypoxia provokes systemic compensatory metabolic reactions throughout the whole body, at the foremost, affecting mechanisms responsible for $\mathrm{O}_{2}$ homeostasis and cellular energy provision.

\section{Alterations in oxygen homeostasis in hypoxia and major depressive disorder}

The next section addresses molecular response mechanisms upon alterations in $\mathrm{O}_{2}$ availability. Additionally, we will outline the link between the cellular response to hypoxia and the energy metabolism. Based on this, it will be demonstrated that changes in the energy metabolism upon hypoxia response might play a role in the pathophysiology of mental disorders, highlighting MDD.

In 2019, the Nobel Prize in physiology or medicine was awarded to Kaelin Jr, Ratcliffe, and Semenza for their work on cellular sensing and adaptation to $\mathrm{O}_{2}$ availability. Their key finding was the discovery of Hypoxia Inducible Factor-1 (HIF-1) as the major mediator of hypoxia response. The heterodimeric transcription factor HIF-1 consists of subunit HIF-1 $\alpha$ and HIF-1 $\beta$, which are ubiquitously expressed [47]. As illustrated in Figure 1, under normoxic conditions, HIF- $1 \alpha$ is rapidly degraded via the proteasome. Depending on $\mathrm{Fe}^{2+}$ and $\mathrm{O}_{2}$, prolyl hydroxylase domain enzymes (PHD) hydroxylate HIF-1 $\alpha$ [48], which serves as a signal for ubiquitination by the von Hippel-Lindau protein (VHL) [49] and the subsequent proteasomal degradation of HIF-1 $\alpha$ [50]. Due to PHD's dependency on molecular $\mathrm{O}_{2}$, hypoxia results in both PHD inhibition and HIF-1 $\alpha$ stabilization [51]. Therefore, $\mathrm{O}_{2}$ sensing can be attributed to PHD. 
Another proposed mechanism for HIF-1 $\alpha$ stabilization is the generation of ROS. Researchers inhibited the hypoxic response by blocking ROS generation at mitochondrial ETC complex III $[52,53]$. Increased production of ROS leads to catalytic inactivation of PHD via oxidation of $\mathrm{Fe}^{2+}$ to $\mathrm{Fe}^{3+}[54]$. Furthermore, it was shown that low $\mathrm{pO}_{2}$ leads to an increased reduction state of ETC's cytochrome $\mathrm{c}$ that results in a preservation of $\mathrm{O}_{2}$ consumption even under lower $\mathrm{O}_{2}$ abundance [53]. These changes in redox status might lead to elevated ROS production, but the mechanisms are still not fully understood. Altogether, these findings place mitochondria as the central element in the response to hypoxia as well as the source of adaptive regulation, which will be addressed next.

Along with HIF-1, HIF-2 is another important regulator of hypoxic response. HIF-1 and HIF-2 activation depend on the tissue, the time course and severity of hypoxic response, and the type of hypoxic response [55]. Therefore, in this article HIF-1 and HIF-2 will be together referred as Hypoxia Inducible Factors (HIFs) in order to ensure simplicity. HIFs fulfill an important part in the adaptation to altered $\mathrm{O}_{2}$ supply and mitochondrial ROS production. They act as transcription factors on certain genes via binding to hypoxia-responsive elements (HRE) that initiate gene expression. This regulates $\mathrm{O}_{2}$ homeostasis as well as parts of the energy metabolism, e.g., glycolysis and anaerobic respiration [56]. HIF-mediated changes in $\mathrm{O}_{2}$ homeostasis result in increasing $\mathrm{O}_{2}$ delivery and/or decreasing $\mathrm{O}_{2}$ consumption [56]. In order to increase $\mathrm{O}_{2}$ delivery, $\mathrm{HIF}$ targets the vascular endothelial growth factor (VEGF) that induces angiogenesis, and erythropoietin (EPO) that induces erythropoiesis [57, 58]. In line with our hypothesis, higher plasma EPO levels were reported in MDD patients compared to controls, indicating increased erythropoiesis in MDD [59]. Although studies are not entirely consistent, there is evidence for higher blood levels of VEGF in MDD [60].

As mentioned above, HIFs also takes part in the regulation of the energy metabolism. Improving the $\mathrm{O}_{2}$ supply in response to deficits appears straightforward, but the implementation of a 
metabolic change seems to be rather complicated. In conditions of insufficient $\mathrm{O}_{2}$ supply, a metabolic shift towards glycolysis and anaerobic respiration counteracts ROS production, diminishes $\mathrm{O}_{2}$ demand, and maintains ATP provision to some extent [56]. Glucose transporter 1 (GLUT1), lactate dehydrogenase A (LDHA), and pyruvate dehydrogenase kinase 1 (PDK1) are important proteins in the energy metabolism and are directly targeted by HIFs. HIF-1 dependent upregulation of LDHA leads to an increased conversion of pyruvate to lactate [61], while induction of PDK1 inhibits the conversion of pyruvate to acetyl CoA [62]. By increasing cellular glucose concentration (through GLUT1), elevated anaerobic respiration (via LDHA), and inhibition of aerobic respiration (via PDK1), HIFs decrease $\mathrm{O}_{2}$ consumption while promoting glycolysis rather than OXPHOS. Higher expression of HIF-1, GLUT1 and LDHA genes were reported in patients with MDD [63]. Researchers recently found the connection between MDD-like phenotypes and increased GLUT-1 expression in an animal model [64]. In line with these results, a study reported downregulation of citric acid cycle metabolites in immune cells of patients with MDD [65]. Findings in certain mental disorders support the hypoxia-mediated shift towards glycolysis. Increased pyruvate was found in the blood of patients with bipolar disorder [66] and posttraumatic stress disorder [67]. A meta-analysis reported decreased pyruvate in the blood of MDD patients [68] which might be due to increased LDHA activity. Increased lactate was found in the blood of posttraumatic stress disorder patients [67], ventricular cerebrospinal fluid of MDD patients [69], and in the brain of schizophrenia and bipolar disorder patients [70].

Taken together, the highly conserved HIF regulation constitutes an essential mechanism for adaption to hypoxic conditions. As a response to decreased $\mathrm{O}_{2}$ availability and/or elevated ROS production, HIF stabilization induces both improvement of the $\mathrm{O}_{2}$ supply and metabolic reprogramming. There is evidence of such metabolic changes in mental disorders indicating a 
possible contribution to the pathophysiology. Please see Table 2 for a summary of hypoxic response related alterations in MDD.

\section{Disturbances in mitochondrial function and biogenesis during hypoxic conditions and major depressive disorder}

This section focuses on mitochondrial functioning, and how it might be influenced by hypoxic response in mental disorders. In general, mitochondrial research in psychology has gained importance in recent years. Many studies report allostatic processes, namely adaptations to certain stressors such as chronic life stress or trauma, which lead to mitochondrial allostatic load and contribute to MDD symptomatology. However, many of these allostatic processes are poorly characterized.

Alterations in mitochondrial function and biogenesis have been established to be critical factors in MDD pathophysiology [71]. These factors are also regulated during hypoxic conditions through HIFs [72]. Therefore, the link between mitochondrial function and the previously described shift towards glycolysis seems plausible. In order to regulate the energy metabolism in hypoxic conditions, citric acid cycle is inhibited via PDK1, and the ETC is remodeled [72]. During hypoxic conditions, ETC adapts its complexes to prevent additional ROS production also while inactivating complex I [73]. Moreover, it was proposed that optimal $\mathrm{O}_{2}$ consumption is achieved under hypoxic conditions via a change in complex IV (COX) subunit COX4-1 to COX4-2 [74] .

However, such hypoxia-related reprogramming comes at the cost of less efficient ATP production, which is also observed in $\operatorname{MDD}[9,10]$. As already described, studies reported a disturbed mitochondrial energy production in several cell types of MDD patients [6-8]. Conceivably, this alteration in MDD could be the result of hypoxic stress-related reprogramming of the mitochondrial complexes. Indeed, downregulation of mitochondrial 
complexes I, III, and IV was reported in gastrocnemius muscle and hippocampus tissue of “depressed" rats [75]. A meta-analysis showed similar effect in humans with MDD, reporting decreased activity in mitochondrial complex I and IV [76].

Another response to hypoxia is the downregulation of ATP-demanding processes. This is achieved by degradation of Na-K-ATPase as well as diminished global mRNA translation through the suppression of rapamycin complex 1 (mTORC1) [77]. These mechanisms might lead to an overall reduction in the regulatory capacity. The mechanism underlying this downregulation is not yet fully understood. Most probably, ROS that are generated during hypoxia at the mitochondrial complex III trigger the increase of cytosolic calcium [78]. Elevated calcium concentration activates $\mathrm{Ca}^{2+} /$ calmodulin-dependent kinase kinase (CaMKK), followed by activation of AMP-activated protein kinase (AMPK) [79]. AMPK itself inhibits mTORC1 and promotes endocytosis of Na-K-ATPase [80].Remarkably, reduced activity of Na-K-ATPase was shown in a rat MDD model [75], and in patients with MDD and schizophrenia [81]. Alterations in the protein's signaling are well established in bipolar disorder [82]. Moreover, decreased expression of the gene coding for Na-K-ATPase was reported in MDD patients compared to controls [83].

As another adaptation to hypoxia, $\mathrm{HIFs}$ limit the overall mitochondrial $\mathrm{O}_{2}$ consumption through decreasing the mitochondrial mass by inducing mitophagy and suppressing mitochondrial biogenesis [72, 84]. Mitophagy refers to mitochondrial autophagy, the process to degrade damaged or unwanted mitochondria [85]. HIFs seem to promote mitophagy through activation of BCL2/adenovirus E1B $19 \mathrm{kDa}$ protein-interacting protein 3 (BNIP3) and BCL2/adenovirus E1B $19 \mathrm{kDa}$ protein-interacting protein 3-like (BNIP3L/NIX) [86, 87] as well as PINK1/Parkin [88]. The role of mitophagy in MDD is not exactly clear. A study reported increased mitophagy induced by acute mental stress in rats [89]. Mitophagy was suggested to be impaired in MDD [90], and higher PINK1 but lower Parkin levels in PBMC were reported in patients compared 
to healthy controls [91]. As for mitochondrial biogenesis, in hypoxic conditions, HIFs suppress peroxisome proliferator-activated receptor gamma coactivator 1 alpha (PGC-1 $\alpha)$, which is the main regulator of mitochondrial biogenesis [92]. This suppression seems to also happen in MDD. Less expression of $P G C-1 \alpha$ and other mitochondrial biogenesis-related genes were observed in individuals with MDD, compared to controls [93]. Moreover, decreased citrate synthase activity was reported in MDD compared to controls, indicating lower mitochondrial mass in MDD [94].

During hypoxic conditions, mitochondrial dynamics are regulated not only to decrease OXPHOS, but also to reduce ROS production and induce mitophagy [72]. Mitochondrial dynamics, namely fusion and fission, rapidly adapt according to altered cellular needs [95]. Mitochondrial fusion helps retaining optimal functionality upon genotoxic events in the mitochondrial DNA through merging with other undamaged mitochondria, sharing their functional proteins. Mitochondrial fission promotes mitophagy to degrade old or damaged mitochondria [96]. In healthy cells, these processes are well-balanced, but severe cellular stress can lead to apoptosis and consequently to increased mitochondrial fission [96]. Hypoxic stress also regulates mitochondrial dynamics by inducing fission [72]. Mitochondrial allostatic load caused by psychological and physiological stress is also thought to lead to accumulation of mitochondrial damage that promotes fission [97]. Increased mitochondrial fission was observed in peripheral CD4+ cells of "anxious" mice, compared to control mice [98]. In addition, decreased expression of a fusion protein was found in nucleus accumbens of highly "anxious" rats [99]. MDD as a disorder associated with mitochondrial allostatic overload might involve similar shifts in mitochondrial dynamics. Indeed, a recent study reported evidence indicating increased fission related mitochondrial fragmentation in MDD [91].

Taken together, we showed several complex mechanisms that occur in mitochondria as a response to hypoxia. Most interestingly, the same mechanisms were associated with mental 
disorders such as MDD (Table 2). However, cells might benefit from these adaptations due to optimization of $\mathrm{O}_{2}$ consumption, downregulation of ROS production, and switching to glycolysis to retain ATP production even in suboptimal conditions for OXPHOS. On the other hand, a conceivable drawback might be a global reduction in a variety of metabolic processes. As a result, such regulations might lead to a diminished response capacity towards additional stressors, which is designated as allostatic load.

***insert Table 2 around here***

\section{Stress-related inflammation and oxidative stress in major depressive disorder might lead to low-grade hypoxia and altered mitochondrial function}

In this section, we will elucidate why the hypoxic response might occur in MDD, and how it is associated with other processes that are related to the disease, specifically inflammation and oxidative stress.

In stress-related disorders, it is commonly accepted that activation of the hypothalamicpituitary-adrenal axis via secretion of stress hormones (e.g. cortisol) can lead to elevated levels of proinflammatory cytokines in the bloodstream, and subsequently to increased oxidative stress [100, 101]. For MDD, meta-analyses ascertained elevated levels of certain proinflammatory parameters [102] as well as increased oxidative stress [103]. Both processes can contribute to altered $\mathrm{O}_{2}$ transport in MDD, thus promoting hypoxia. Chronic inflammation might lead to anemia through indirect downregulation of erythropoiesis [104], most likely by influencing the iron homeostasis [105]. Consequently, elevated ROS are capable of damaging hemoglobin-containing erythrocytes that are essential for $\mathrm{O}_{2}$ transport [106]. Both oxidative stress and hypoxia may result in metabolic reprogramming via induction of HIFs as already described before. Moreover, this reprogramming probably counteracts increased production of ROS and maintaining optimal ATP production under hypoxic conditions. 
Our model (Figure 2) proposes that chronic stress leads to low-grade inflammation, elevated oxidative stress, and impaired $\mathrm{O}_{2}$ transport, promoting a low-grade hypoxic state. To counteract these challenges, hypoxic response leads to a metabolic shift towards glycolysis, anaerobic respiration, mitochondrial fission and mitophagy, decreased mitochondrial functioning and content, and a diminished ATP production. Hypoxia can in turn induce inflammation [107] and oxidative stress [108], leading to a vicious cycle which can elucidate the pathophysiology of MDD. This model can also help explain the etiology of comorbid MDD, or other related symptomatology such as cognitive symptoms and fatigue, in infectious diseases such as COVID-19 [36, 109]. Inflammation in COVID-19 can cause damage in the lungs and endothelium [110], limiting the $\mathrm{O}_{2}$ transport to the circulation. Decreased $\mathrm{O}_{2}$ levels in tissues might then provoke a hypoxic response [111] through altered mitochondrial function and ROS production [112], leading to a vicious cycle. Inflammation and oxidative stress-related neurotoxic events as well as lack of energy to fulfill certain physiological processes can explain the MDD symptomatology in COVID-19.

In this perspective, we mainly focused on alterations in $\mathrm{O}_{2}$ transport which can lead to a possible hypoxic state in MDD. Other diseases have been previously associated with hypoxia, and its role in their pathophysiology have been discussed. For instance, it has been suggested that hypoxia in sepsis, termed "cytopathic hypoxia", might be the outcome of deficits in mitochondrial respiration rather than $\mathrm{O}_{2}$ transport [113]. Although it is accepted that inefficient production of mitochondrial ATP is not responsible for hypoxia signaling, inflammation-related damage in mitochondrial membrane and altered complex activities might increase mitochondrial ROS production while cellular $\mathrm{O}_{2}$ consumption is reduced [114]. Consequently, ROS might act as signaling molecules even in normoxic conditions, leading to stabilization of HIF-1 $\alpha$. Inflammation-related microvascular flow abnormalities in MDD [115] can also lead to dysregulation in cellular $\mathrm{O}_{2}$ utilization leading to hypoxia. However, inflammation-related 
deficits in $\mathrm{O}_{2}$ utilization and our model involving $\mathrm{O}_{2}$ transport are not mutually exclusive. Since MDD is a heterogeneous disorder, either or both processes can occur.

***insert Figure 2 around here***

\section{Conclusion}

MDD as a stress-related mental disorder entails multiple physical and psychological symptoms that arise out of various biochemical alterations. Chronic or long-term stress prevalent in MDD is likely to result in inflammation and oxidative stress, and this can lead to maladaptive alterations in transport and utilization of the mitochondrial fuel $\mathrm{O}_{2}$, possibly provoking hypoxic response. Hypoxia can in turn reduce mitochondrial mass, shift the energy production from mitochondrial respiration towards anaerobic respiration, influence mitochondrial structure and function, and limit the overall energy demand. To date, the body of available evidence on $\mathrm{O}_{2}$ transport and homeostasis as well as mitochondrial function is limited to mostly cross-sectional and correlational designs. Therefore, longitudinal and intervention studies, which also consider the heterogeneity of the disease, are needed for more reliable findings. Our upcoming project (Kaupp et al., in preparation) aims to assess the validity of our model conceptualizing MDD as a low-grade hypoxic condition using a longitudinal randomized controlled trial where we treat MDD patients with cognitive-behavioral therapy. We aim to describe the causal relationship between psychological stress, mitochondrial function, and $\mathrm{O}_{2}$ homeostasis as well as identify reliable biomarkers of MDD, altogether expanding our understanding of MDD pathophysiology. Thereby, our research might inspire the development of improved and individualized treatment strategies for this highly heterogeneous disease. 


\section{References}

1. Olesen J, Gustavsson A, Svensson M, Wittchen H-U, Jönsson B, CDBE2010 study group, et al. The economic cost of brain disorders in Europe. Eur J Neurol. 2012;19:155-162.

2. Schildkraut JJ. The catecholamine hypothesis of affective disorders: a review of supporting evidence. Am J Psychiatry. 1965;122:509-522.

3. Coppen A. The biochemistry of affective disorders. Br J Psychiatry J Ment Sci. 1967;113:1237-1264.

4. Fournier JC, DeRubeis RJ, Hollon SD, Dimidjian S, Amsterdam JD, Shelton RC, et al. Antidepressant drug effects and depression severity: a patient-level meta-analysis. JAMA. 2010;303:47-53.

5. Insel TR, Wang PS. The STAR* $D$ trial: revealing the need for better treatments. Psychiatr Serv Wash DC. 2009;60:1466-1467.

6. Gardner A, Johansson A, Wibom R, Nennesmo I, von Döbeln U, Hagenfeldt L, et al. Alterations of mitochondrial function and correlations with personality traits in selected major depressive disorder patients. J Affect Disord. 2003;76:55-68.

7. Karabatsiakis A, Böck C, Salinas-Manrique J, Kolassa S, Calzia E, Dietrich DE, et al. Mitochondrial respiration in peripheral blood mononuclear cells correlates with depressive subsymptoms and severity of major depression. Transl Psychiatry. 2014;4:e397.

8. Hroudová J, Fišar Z, Kitzlerová E, Zvěřová M, Raboch J. Mitochondrial respiration in blood platelets of depressive patients. Mitochondrion. 2013;13:795-800.

9. Moore CM, Christensen JD, Lafer B, Fava M, Renshaw PF. Lower levels of nucleoside triphosphate in the basal ganglia of depressed subjects: a phosphorous-31 magnetic resonance spectroscopy study. Am J Psychiatry. 1997;154:116-118.

10. Volz HP, Rzanny R, Riehemann S, May S, Hegewald H, Preussler B, et al. 31P magnetic resonance spectroscopy in the frontal lobe of major depressed patients. Eur Arch Psychiatry Clin Neurosci. 1998;248:289-295.

11. Firth J, Firth JA, Stubbs B, Vancampfort D, Schuch FB, Hallgren M, et al. Association Between Muscular Strength and Cognition in People With Major Depression or Bipolar Disorder and Healthy Controls. JAMA Psychiatry. 2018;75:740-746.

12. Bonora M, Patergnani S, Rimessi A, De Marchi E, Suski JM, Bononi A, et al. ATP synthesis and storage. Purinergic Signal. 2012;8:343-357.

13. Wilson DF. Oxidative phosphorylation: regulation and role in cellular and tissue metabolism. J Physiol. 2017;595:7023-7038.

14. Biro GP. From the Atmosphere to the Mitochondrion: The Oxygen Cascade. In: Kim HW, Greenburg AG, editors. Hemoglobin-Based Oxyg. Carr. Red Cell Substit. Oxyg. Ther., Berlin, Heidelberg: Springer Berlin Heidelberg; 2013. p. 27-53.

15. Knutson MD. Iron transport proteins: Gateways of cellular and systemic iron homeostasis. J Biol Chem. 2017;292:12735-12743.

16. Rausch JL, Johnson ME, Corley KM, Hobby HM, Shendarkar N, Fei Y, et al. Depressed Patients Have Higher Body Temperature: 5-HT Transporter Long Promoter Region Effects. Neuropsychobiology. 2003;47:120-127.

17. Shiloh R, Kushnir T, Gilat $Y$, Gross-Isseroff R, Hermesh H, Munitz H, et al. In vivo occipital-frontal temperature-gradient in schizophrenia patients and its possible association with psychopathology: A magnetic resonance spectroscopy study. Eur Neuropsychopharmacol. 2008;18:557-564.

18. Hagihara H, Catts VS, Katayama Y, Shoji H, Takagi T, Huang FL, et al. Decreased Brain $\mathrm{pH}$ as a Shared Endophenotype of Psychiatric Disorders. Neuropsychopharmacology. 2018;43:459-468.

19. Histogenous Hypoxia in Depression: A Cross-Sectional Paired Study into Venous Blood Gases in Outpatients with Depression. https://www.jneuropsychiatry.org/peerreview/histogenous-hypoxia-in-depression-a-crosssectional-paired-study-into-venousblood-gases-in-outpatients-with-depression-12232.html. Accessed 22 July 2021. 
20. Russian Academy of Sciences, Institute of Theoretical and Experimental Biophysics, Pushchino, Russia, Kaminsky Y. Age-Related Defects in Erythrocyte 2,3-

Diphosphoglycerate Metabolism in Dementia. Aging Dis. 2013;04:244-255.

21. Maes M, Van de Vyvere J, Vandoolaeghe E, Bril T, Demedts P, Wauters A, et al. Alterations in iron metabolism and the erythron in major depression: Further evidence for a chronic inflammatory process. J Affect Disord. 1996;40:23-33.

22. Vahdat Shariatpanaahi M, Vahdat Shariatpanaahi Z, Moshtaaghi M, Shahbaazi SH, Abadi A. The relationship between depression and serum ferritin level. Eur J Clin Nutr. 2007;61:532-535.

23. Shafiee M, Tayefi M, Hassanian SM, Ghaneifar Z, Parizadeh MR, Avan A, et al. Depression and anxiety symptoms are associated with white blood cell count and red cell distribution width: A sex-stratified analysis in a population-based study.

Psychoneuroendocrinology. 2017;84:101-108.

24. Wainberg M, Kloiber S, Diniz B, Mclntyre RS, Felsky D, Tripathy SJ. Clinical laboratory tests and five-year incidence of major depressive disorder: a prospective cohort study of 433,890 participants from the UK Biobank. Transl Psychiatry. 2021;11:380.

25. Islam MR, Islam MR, Shalahuddin Qusar MMA, Islam MS, Kabir MH, Mustafizur Rahman GKM, et al. Alterations of serum macro-minerals and trace elements are associated with major depressive disorder: a case-control study. BMC Psychiatry. 2018;18:94.

26. Janet R. Hunt PhD R, PhD JGP. Iron Status and Depression in Premenopausal Women: An MMPI Study. Behav Med. 1999;25:62-68.

27. Duport N, Preziosi P, Boutron-Ruault M-C, Bertrais S, Galan P, Favier A, et al. Consequences of iron depletion on health in menstruating women. Eur $\mathrm{J}$ Clin Nutr. 2003;57:1169-1175.

28. Yao S, Zhong Y, Xu Y, Qin J, Zhang N, Zhu X, et al. Quantitative Susceptibility Mapping Reveals an Association between Brain Iron Load and Depression Severity. Front Hum Neurosci. 2017;11:442.

29. Vela D. The Dual Role of Hepcidin in Brain Iron Load and Inflammation. Front Neurosci. 2018;12:740.

30. Hentze MW, Muckenthaler MU, Galy B, Camaschella C. Two to Tango: Regulation of Mammalian Iron Metabolism. Cell. 2010;142:24-38.

31. Farajdokht F, Soleimani M, Mehrpouya S, Barati M, Nahavandi A. The role of hepcidin in chronic mild stress-induced depression. Neurosci Lett. 2015;588:120-124.

32. Hidese S, Saito K, Asano S, Kunugi H. Association between iron-deficiency anemia and depression: A web-based Japanese investigation: Iron-deficiency anemia and depression. Psychiatry Clin Neurosci. 2018;72:513-521.

33. Katz T, Schatz JC. Overlapping Biological Mechanisms Underlying Sickle Cell Disease, Stress, and Depression: A Stress-Vulnerability Framework. Harv Rev Psychiatry. 2014;22:205-215.

34. Wong SYS, Woo J, Lynn HSH, Leung J, Tang YN, Leung PC. Risk of depression in patients with chronic respiratory diseases: results from two large cohort studies in Chinese elderly from Hong Kong. Int J Geriatr Psychiatry. 2006;21:233-238.

35. Zielinski TA, Brown S, Nejtek VA, Kahn DA, Moore JJ, Rush AJ. Depression in Asthma: Prevalence and Clinical Implications. Prim Care Companion J Clin Psychiatry. 2000;02:153-158.

36. Bueno-Notivol J, Gracia-García P, Olaya B, Lasheras I, López-Antón R, Santabárbara J. Prevalence of depression during the COVID-19 outbreak: A meta-analysis of community-based studies. Int J Clin Health Psychol. 2021;21:100196.

37. Webb RT, Kontopantelis E, Doran T, Qin P, Creed F, Kapur N. Suicide risk in primary care patients with major physical diseases: a case-control study. Arch Gen Psychiatry. 2012;69:256-264.

38. Yolton K, Khoury JC, Burkle J, LeMasters G, Cecil K, Ryan P. lifetime exposure to traffic-related air pollution and symptoms of depression and anxiety at age 12 years. Environ Res. 2019;173:199-206. 
39. Kim C, Jung SH, Kang DR, Kim HC, Moon KT, Hur NW, et al. Ambient particulate matter as a risk factor for suicide. Am J Psychiatry. 2010;167:1100-1107.

40. Brenner B, Cheng D, Clark S, Camargo CA. Positive association between altitude and suicide in 2584 U.S. counties. High Alt Med Biol. 2011;12:31-35.

41. Kious BM, Bakian A, Zhao J, Mickey B, Guille C, Renshaw P, et al. Altitude and risk of depression and anxiety: findings from the intern health study. Int Rev Psychiatry Abingdon Engl. 2019;31:637-645.

42. Young S. Elevated incidence of suicide in people living at altitude, smokers and patients with chronic obstructive pulmonary disease and asthma: possible role of hypoxia causing decreased serotonin synthesis. J Psychiatry Neurosci. 2013;38:423426.

43. Dos Santos Quaresma M, Souza W, Lemos V, Caris A, Thomatieli-Santos R. The Possible Importance of Glutamine Supplementation to Mood and Cognition in Hypoxia from High Altitude. Nutrients. 2020;12:3627.

44. Kious BM, Kondo DG, Renshaw PF. Living High and Feeling Low: Altitude, Suicide, and Depression. Harv Rev Psychiatry. 2018;26:43-56.

45. Tomioka H, Yamagata B, Kawasaki S, Pu S, Iwanami A, Hirano J, et al. A Longitudinal Functional Neuroimaging Study in Medication-Naïve Depression after Antidepressant Treatment. PLOS ONE. 2015;10:e0120828.

46. Husain SF, Yu R, Tang T-B, Tam WW, Tran B, Quek TT, et al. Validating a functional near-infrared spectroscopy diagnostic paradigm for Major Depressive Disorder. Sci Rep. 2020;10:9740.

47. Wang GL, Semenza GL. Purification and characterization of hypoxia-inducible factor 1. J Biol Chem. 1995;270:1230-1237.

48. Bruick RK, McKnight SL. A conserved family of prolyl-4-hydroxylases that modify HIF. Science. 2001;294:1337-1340.

49. Hon W-C, Wilson MI, Harlos K, Claridge TDW, Schofield CJ, Pugh CW, et al. Structural basis for the recognition of hydroxyproline in HIF-1 alpha by pVHL. Nature. 2002;417:975-978.

50. Maxwell PH, Wiesener MS, Chang GW, Clifford SC, Vaux EC, Cockman ME, et al. The tumour suppressor protein VHL targets hypoxia-inducible factors for oxygendependent proteolysis. Nature. 1999;399:271-275.

51. Kaelin WG, Ratcliffe PJ. Oxygen sensing by metazoans: the central role of the HIF hydroxylase pathway. Mol Cell. 2008;30:393-402.

52. Orr AL, Vargas L, Turk CN, Baaten JE, Matzen JT, Dardov VJ, et al. Suppressors of superoxide production from mitochondrial complex III. Nat Chem Biol. 2015;11:834836.

53. Waypa GB, Smith KA, Schumacker PT. O 2 sensing, mitochondria and ROS signaling: The fog is lifting. Mol Aspects Med. 2016;47-48:76-89.

54. Gerald D, Berra E, Frapart YM, Chan DA, Giaccia AJ, Mansuy D, et al. JunD reduces tumor angiogenesis by protecting cells from oxidative stress. Cell. 2004;118:781-794.

55. Koh MY, Powis G. Passing the baton: the HIF switch. Trends Biochem Sci. 2012;37:364-372.

56. Prabhakar NR, Semenza GL. Oxygen Sensing and Homeostasis. Physiology. 2015;30:340-348.

57. Rankin EB, Biju MP, Liu Q, Unger TL, Rha J, Johnson RS, et al. Hypoxia-inducible factor-2 (HIF-2) regulates hepatic erythropoietin in vivo. J Clin Invest. 2007;117:10681077.

58. Semenza GL, Wang GL. A nuclear factor induced by hypoxia via de novo protein synthesis binds to the human erythropoietin gene enhancer at a site required for transcriptional activation. Mol Cell Biol. 1992;12:5447-5454.

59. Lee B-H, Park Y-M, Hwang J-A, Kim Y-K. Variable alterations in plasma erythropoietin and brain-derived neurotrophic factor levels in patients with major depressive disorder with and without a history of suicide attempt. Prog Neuropsychopharmacol Biol Psychiatry. 2021;110:110324. 
60. Takebayashi M, Hashimoto R, Hisaoka K, Tsuchioka M, Kunugi H. Plasma levels of vascular endothelial growth factor and fibroblast growth factor 2 in patients with major depressive disorders. J Neural Transm. 2010;117:1119-1122.

61. Firth JD, Ebert BL, Ratcliffe PJ. Hypoxic regulation of lactate dehydrogenase A. Interaction between hypoxia-inducible factor 1 and cAMP response elements. J Biol Chem. 1995;270:21021-21027.

62. Kim J, Tchernyshyov I, Semenza GL, Dang CV. HIF-1-mediated expression of pyruvate dehydrogenase kinase: a metabolic switch required for cellular adaptation to hypoxia. Cell Metab. 2006;3:177-185.

63. Shibata T, Yamagata H, Uchida S, Otsuki K, Hobara T, Higuchi F, et al. The alteration of hypoxia inducible factor-1 (HIF-1) and its target genes in mood disorder patients.

Prog Neuropsychopharmacol Biol Psychiatry. 2013;43:222-229.

64. Głombik K, Detka J, Góralska J, Kurek A, Solnica B, Budziszewska B. Brain Metabolic Alterations in Rats Showing Depression-Like and Obesity Phenotypes. Neurotox Res. 2020;37:406-424.

65. Zheng P, Fang Z, Xu X-J, Liu M-L, Du X, Zhang X, et al. Metabolite signature for diagnosing major depressive disorder in peripheral blood mononuclear cells. J Affect Disord. 2016;195:75-81.

66. Yoshimi N, Futamura T, Kakumoto K, Salehi AM, Sellgren CM, Holmén-Larsson J, et al. Blood metabolomics analysis identifies abnormalities in the citric acid cycle, urea cycle, and amino acid metabolism in bipolar disorder. BBA Clin. 2016;5:151-158.

67. Mellon SH, Bersani FS, Lindqvist D, Hammamieh R, Donohue D, Dean K, et al. Metabolomic analysis of male combat veterans with post traumatic stress disorder. PLOS ONE. 2019;14:e0213839.

68. Pu J, Liu Y, Zhang H, Tian L, Gui S, Yu Y, et al. An integrated meta-analysis of peripheral blood metabolites and biological functions in major depressive disorder. Mol Psychiatry. 2020. 20 January 2020. https://doi.org/10.1038/s41380-020-0645-4.

69. Bradley KAL, Mao X, Case JAC, Kang G, Shungu DC, Gabbay V. Increased ventricular cerebrospinal fluid lactate in depressed adolescents. Eur Psychiatry. 2016;32:1-8.

70. Dogan AE, Yuksel C, Du F, Chouinard V-A, Öngür D. Brain lactate and pH in schizophrenia and bipolar disorder: a systematic review of findings from magnetic resonance studies. Neuropsychopharmacology. 2018;43:1681-1690.

71. Allen J, Caruncho HJ, Kalynchuk LE. Severe life stress, mitochondrial dysfunction, and depressive behavior: A pathophysiological and therapeutic perspective. Mitochondrion. 2021;56:111-117.

72. Fuhrmann DC, Brüne B. Mitochondrial composition and function under the control of hypoxia. Redox Biol. 2017;12:208-215.

73. Stepanova A, Konrad C, Guerrero-Castillo S, Manfredi G, Vannucci S, Arnold S, et al. Deactivation of mitochondrial complex I after hypoxia-ischemia in the immature brain. J Cereb Blood Flow Metab. 2019;39:1790-1802.

74. Douiev L, Miller C, Ruppo S, Benyamini H, Abu-Libdeh B, Saada A. Upregulation of COX4-2 via HIF-1 $\alpha$ in Mitochondrial COX4-1Deficiency. 2021. 10 February 2021.

75. Yuan Q, Li Y, Deng X, Shi H, Zhao Z, Wang C, et al. Effects of Xingpi Kaiyu Fang on ATP, Na/K-ATPase, and Respiratory Chain Complexes of Hippocampus and Gastrocnemius Muscle in Depressed Rats. Evid-Based Complement Altern Med ECAM. 2019;2019:6054926.

76. Holper L, Ben-Shachar D, Mann J. Multivariate meta-analyses of mitochondrial complex I and IV in major depressive disorder, bipolar disorder, schizophrenia, Alzheimer disease, and Parkinson disease. Neuropsychopharmacology. 2019;44:837849.

77. Comellas AP, Dada LA, Lecuona E, Pesce LM, Chandel NS, Quesada N, et al. Hypoxia-mediated degradation of $\mathrm{Na}, \mathrm{K}-\mathrm{ATP}$ ase via mitochondrial reactive oxygen species and the ubiquitin-conjugating system. Circ Res. 2006;98:1314-1322. 
78. Waypa GB, Marks JD, Mack MM, Boriboun C, Mungai PT, Schumacker PT. Mitochondrial Reactive Oxygen Species Trigger Calcium Increases During Hypoxia in Pulmonary Arterial Myocytes. Circ Res. 2002;91:719-726.

79. Hawley SA, Pan DA, Mustard KJ, Ross L, Bain J, Edelman AM, et al. Calmodulindependent protein kinase kinase-beta is an alternative upstream kinase for AMPactivated protein kinase. Cell Metab. 2005;2:9-19.

80. Gusarova GA, Dada LA, Kelly AM, Brodie C, Witters LA, Chandel NS, et al. a1-AMPActivated Protein Kinase Regulates Hypoxia-Induced Na,K-ATPase Endocytosis via Direct Phosphorylation of Protein Kinase C\}. Mol Cell Biol. 2009;29:3455-3464.

81. Rybakowski JK, Lehmann W. Decreased Activity of Erythrocyte Membrane ATPases in Depression and Schizophrenia. Neuropsychobiology. 1994;30:11-14.

82. Lichtstein D, Ilani A, Rosen H, Horesh N, Singh S, Buzaglo N, et al. Na+, K+-ATPase Signaling and Bipolar Disorder. Int J Mol Sci. 2018;19:2314.

83. Zhao J, Guo X, Du Y, Han Y, Wang Y, Li L, et al. Correlative study of peripheral ATP1A1 gene expression level to anxiety severity score on major depressive disorder patients. J Basic Clin Physiol Pharmacol. 2016;27.

84. Thomas LW, Ashcroft M. Exploring the molecular interface between hypoxia-inducible factor signalling and mitochondria. Cell Mol Life Sci. 2019;76:1759-1777.

85. Palikaras K, Lionaki E, Tavernarakis N. Balancing mitochondrial biogenesis and mitophagy to maintain energy metabolism homeostasis. Cell Death Differ. 2015;22:1399-1401.

86. Sowter HM, Ratcliffe PJ, Watson P, Greenberg AH, Harris AL. HIF-1-dependent regulation of hypoxic induction of the cell death factors BNIP3 and NIX in human tumors. Cancer Res. 2001;61:6669-6673.

87. Bellot G, Garcia-Medina R, Gounon P, Chiche J, Roux D, Pouysségur J, et al. Hypoxia-induced autophagy is mediated through hypoxia-inducible factor induction of BNIP3 and BNIP3L via their BH3 domains. Mol Cell Biol. 2009;29:2570-2581.

88. Linqing L, Yuhan Q, Erfei L, Yong Q, Dong W, Chengchun T, et al. Hypoxia-induced PINK1/Parkin-mediated mitophagy promotes pulmonary vascular remodeling. Biochem Biophys Res Commun. 2021;534:568-575.

89. De R, Mazumder S, Sarkar S, Debsharma S, Siddiqui AA, Saha SJ, et al. Acute mental stress induces mitochondrial bioenergetic crisis and hyper-fission along with aberrant mitophagy in the gut mucosa in rodent model of stress-related mucosal disease. Free Radic Biol Med. 2017;113:424-438.

90. Doblado L, Lueck C, Rey C, Samhan-Arias AK, Prieto I, Stacchiotti A, et al. Mitophagy in Human Diseases. Int J Mol Sci. 2021;22:3903.

91. Scaini G, Mason BL, Diaz AP, Jha MK, Soares JC, Trivedi MH, et al. Dysregulation of mitochondrial dynamics, mitophagy and apoptosis in major depressive disorder: Does inflammation play a role? Mol Psychiatry. 2021. 14 October 2021.

https://doi.org/10.1038/s41380-021-01312-w.

92. LaGory EL, Wu C, Taniguchi CM, Ding C-KC, Chi J-T, von Eyben R, et al. Suppression of PGC-1a Is Critical for Reprogramming Oxidative Metabolism in Renal Cell Carcinoma. Cell Rep. 2015;12:116-127.

93. Alcocer-Gómez E, Núñez-Vasco J, Casas-Barquero N, Williams MR, Navarro-Pando JM, Bullón P, et al. Gene Expression Profile in Major Depressive Disorder Shows Reduced Mitochondrial Biogenesis. CNS Neurosci Ther. 2016;22:636-638.

94. Zvěřová $M$, Hroudová J, Fišar Z, Hansíková $H$, Kališová L, Kitzlerová E, et al. Disturbances of mitochondrial parameters to distinguish patients with depressive episode of bipolar disorder and major depressive disorder. Neuropsychiatr Dis Treat. 2019; Volume 15:233-240.

95. Tilokani L, Nagashima S, Paupe V, Prudent J. Mitochondrial dynamics: overview of molecular mechanisms. Essays Biochem. 2018;62:341-360.

96. Youle RJ, van der Bliek AM. Mitochondrial Fission, Fusion, and Stress. Science. 2012;337:1062-1065.

97. Picard M, Juster R-P, McEwen BS. Mitochondrial allostatic load puts the 'gluc' back in glucocorticoids. Nat Rev Endocrinol. 2014;10:303-310. 
98. Fan K, Li Y, Wang H, Mao X, Guo J, Wang F, et al. Stress-Induced Metabolic Disorder in Peripheral CD4+ T Cells Leads to Anxiety-like Behavior. Cell. 2019;179:864879.e19.

99. Gebara E, Zanoletti O, Ghosal S, Grosse J, Schneider BL, Knott G, et al. Mitofusin-2 in the Nucleus Accumbens Regulates Anxiety and Depression-like Behaviors Through Mitochondrial and Neuronal Actions. Biol Psychiatry. 2021;89:1033-1044.

100. Czarny P, Kwiatkowski D, Kacperska D, Kawczyńska D, Talarowska M, Orzechowska A, et al. Elevated level of DNA damage and impaired repair of oxidative DNA damage in patients with recurrent depressive disorder. Med Sci Monit Int Med J Exp Clin Res. 2015;21:412-418.

101. Miller MW, Sadeh N. Traumatic stress, oxidative stress and post-traumatic stress disorder: neurodegeneration and the accelerated-aging hypothesis. Mol Psychiatry. 2014;19:1156-1162.

102. Osimo EF, Pillinger T, Rodriguez IM, Khandaker GM, Pariante CM, Howes OD. Inflammatory markers in depression: A meta-analysis of mean differences and variability in 5,166 patients and 5,083 controls. Brain Behav Immun. 2020;87:901-909.

103. Black CN, Bot M, Scheffer PG, Cuijpers P, Penninx BWJH. Is depression associated with increased oxidative stress? A systematic review and meta-analysis. Psychoneuroendocrinology. 2015;51:164-175.

104. Weiss G, Ganz T, Goodnough LT. Anemia of inflammation. Blood. 2019;133:40-50.

105. Ganz T. Hepcidin and iron regulation, 10 years later. Blood. 2011;117:4425-4433.

106. Mohanty JG, Nagababu E, Rifkind JM. Red blood cell oxidative stress impairs oxygen delivery and induces red blood cell aging. Front Physiol. 2014;5.

107. Eltzschig HK, Carmeliet P. Hypoxia and Inflammation. N Engl J Med. 2011;364:656665.

108. Guzy RD, Schumacker PT. Oxygen sensing by mitochondria at complex III: the paradox of increased reactive oxygen species during hypoxia: Mitochondrial oxygen sensing. Exp Physiol. 2006;91:807-819.

109. Taquet M, Luciano S, Geddes JR, Harrison PJ. Bidirectional associations between COVID-19 and psychiatric disorder: retrospective cohort studies of 62354 COVID-19 cases in the USA. Lancet Psychiatry. 2021;8:130-140.

110. Jin Y, Ji W, Yang H, Chen S, Zhang W, Duan G. Endothelial activation and dysfunction in COVID-19: from basic mechanisms to potential therapeutic approaches. Signal Transduct Target Ther. 2020;5:293.

111. Tian M, Liu W, Li X, Zhao P, Shereen MA, Zhu C, et al. HIF-1a promotes SARS-CoV-2 infection and aggravates inflammatory responses to COVID-19. Signal Transduct Target Ther. 2021;6:308.

112. Gibellini L, De Biasi S, Paolini A, Borella R, Boraldi F, Mattioli M, et al. Altered bioenergetics and mitochondrial dysfunction of monocytes in patients with COVID-19 pneumonia. EMBO Mol Med. 2020;12.

113. Fink MP. Cytopathic Hypoxia. Crit Care Clin. 2001;17:219-237.

114. Raffaella T, Fiore F, Fabrizia M, Francesco P, Arcangela I, Salvatore S, et al. Induction of mitochondrial dysfunction and oxidative stress in human fibroblast cultures exposed to serum from septic patients. Life Sci. 2012;91:237-243.

115. Empana J-P, Boutouyrie P, Lemogne C, Jouven X, van Sloten TT. Microvascular Contribution to Late-Onset Depression: Mechanisms, Current Evidence, Association With Other Brain Diseases, and Therapeutic Perspectives. Biol Psychiatry. 2021;90:214-225.

116. Cooper G. The Mechanism of Oxidative Phosphorylation. Cell Mol. Approach, . 2nd ed.Sunderland (MA): Sinauer Associates; 2000.

117. Fraisl P, Mazzone M, Schmidt T, Carmeliet P. Regulation of Angiogenesis by Oxygen and Metabolism. Dev Cell. 2009;16:167-179.

118. Valent P, Büsche G, Theurl I, Uras IZ, Germing U, Stauder R, et al. Normal and pathological erythropoiesis in adults: from gene regulation to targeted treatment concepts. Haematologica. 2018;103:1593-1603. 
119. Wang W, Knovich MA, Coffman LG, Torti FM, Torti SV. Serum ferritin: Past, present and future. Biochim Biophys Acta BBA - Gen Subj. 2010;1800:760-769.

120. Gkouvatsos K, Papanikolaou G, Pantopoulos K. Regulation of iron transport and the role of transferrin. Biochim Biophys Acta BBA - Gen Subj. 2012;1820:188-202.

121. Kahl KG, Bens S, Ziegler K, Rudolf S, Kordon A, Dibbelt L, et al. Angiogenic factors in patients with current major depressive disorder comorbid with borderline personality disorder. Psychoneuroendocrinology. 2009;34:353-357. 


\section{Table 1: Explanation of Important Terms.}

\begin{tabular}{|c|c|}
\hline $\begin{array}{l}\text { Glycolysis, } \\
\text { pyruvate oxidation } \\
\text { and citric acid cycle }\end{array}$ & $\begin{array}{l}\text { One glucose forms two pyruvates during glycolysis. In aerobic } \\
\text { conditions, pyruvate is oxidized to acetyl coenzyme A (Acetyl CoA) } \\
\text { with the help of pyruvate dehydrogenase and } \mathrm{NAD}^{+} \text {. Acetyl CoA } \\
\text { then enters the citric acid cycle. During metabolization of } \\
\text { carbohydrates by glycolysis and citric acid cycle, reduction } \\
\text { equivalents (NADH and } \mathrm{FADH}_{2} \text { ) are formed to serve as fuel for } \\
\text { subsequent mitochondrial ATP production [116]. }\end{array}$ \\
\hline $\begin{array}{l}\text { Oxidative } \\
\text { phoshporylation } \\
\text { (OXPHOS) }\end{array}$ & $\begin{array}{l}\text { Electrons provided by NADH and } \mathrm{FADH}_{2} \text { are continuously } \\
\text { transported across the mitochondrial electron transport chain (ETC) } \\
\text { and terminally transferred to } \mathrm{O}_{2} \text {. During this process, a proton } \\
\text { gradient is established and used to synthesize ATP [116]. }\end{array}$ \\
\hline ETC complexes & $\begin{array}{l}\text { ETC consists of four protein complexes that transfer electrons, and } \\
\text { pump protons from mitochondrial matrix to intermembrane space } \\
\text { using the free energy released after the electron transfer, thus } \\
\text { establishing the proton gradient (except for Complex II). NADH is } \\
\text { oxidized in Complex I and its electrons are transferred to Coenzyme } \\
\text { Q (CoQ). Succinate, an intermediate of the citric acid cycle, transfers } \\
\text { electrons to FADH }{ }_{2} \text { in Complex II to be carried to CoQ. The } \\
\text { electrons from } \mathrm{CoQ}_{\text {are transferred to Complex III. Cytochrome c }} \\
\text { accepts electrons from Complex III and donates electrons to } \\
\text { Complex IV. There, the final electron carrier } \mathrm{O}_{2} \text { is reduced to } \mathrm{H}_{2} \mathrm{O} \text {. } \\
\text { Finally, ATP synthase (i.e., Complex V) uses the proton gradient } \\
\text { formed by ETC complexes to catalyze ATP production from ADP } \\
\text { and a phosphate group [116]. }\end{array}$ \\
\hline $\begin{array}{l}\text { Anaerobic } \\
\text { respiration (lactate } \\
\text { formation) }\end{array}$ & $\begin{array}{l}\text { In conditions where } \mathrm{O}_{2} \text { is scarce, pyruvate from glycolysis is } \\
\text { fermented to form lactate, with the help of lactate dehydrogenase and } \\
\mathrm{NADH}[116] \text {. }\end{array}$ \\
\hline Angiogenesis & $\begin{array}{l}\text { Formation of new blood vessels. This process helps with tissue } \\
\text { oxygenation. When } \mathrm{O}_{2} \text { is scarce, certain cells (including neurons) } \\
\text { secrete vascular endothelial growth factor (VEGF), regulated by } \\
\text { HIFs, to trigger angiogenesis [117]. }\end{array}$ \\
\hline Erythropoiesis & $\begin{array}{l}\text { Production of erythrocytes (red blood cells) that start at the bone } \\
\text { marrow and end at the blood stream. Hematopoietic stem cells are }\end{array}$ \\
\hline
\end{tabular}




\begin{tabular}{l|l}
\hline & $\begin{array}{l}\text { differentiated into reticulocytes, which lose their organelles and turn } \\
\text { into hemoglobin-containing mature erythrocytes that are released in } \\
\text { blood stream. Erythropoietin (EPO) is the main regulator of the } \\
\text { process. Iron proteins and certain vitamins (e.g. Vitamin B12) are } \\
\text { also regulators of erythropoiesis [118]. }\end{array}$ \\
\hline Ferritin & $\begin{array}{l}\text { The iron storage protein. Its levels are mostly controlled by the iron } \\
\text { content in the body, like the many iron proteins. Another function of } \\
\text { ferritin is to protect the cell components from iron-induced oxidative } \\
\text { damage [119]. }\end{array}$ \\
\hline Transferrin & $\begin{array}{l}\text { Transports iron in plasma to bone marrow for erythropoiesis and to } \\
\text { the other cells. Other functions of the protein are iron uptake from } \\
\text { the gut where absorption occurs, and regulation of hepcidin [120]. }\end{array}$ \\
\hline Hepcidin & $\begin{array}{l}\text { The main regulator of systemic iron homeostasis. Its role is to } \\
\text { maintain iron absorption and release. Therefore, it protects the body } \\
\text { from iron overload and deficiency [120]. }\end{array}$ \\
\hline
\end{tabular}


Table 2. Summary of Findings Regarding Hypoxia Related Processes in Major Depressive Disorder

\begin{tabular}{|c|c|c|}
\hline $\begin{array}{l}\text { Adaptations related to } \\
\text { hypoxic response }\end{array}$ & $\begin{array}{l}\text { Provoked process } \\
\text { in hypoxia }\end{array}$ & $\begin{array}{l}\text { Findings in MDD patients } \\
\text { compared to controls }\end{array}$ \\
\hline \multirow[t]{2}{*}{ Increased $\mathrm{O}_{2}$ delivery } & Erythropoiesis & Increased plasma EPO [59] \\
\hline & Angiogenesis & $\begin{array}{l}\text { Increased serum [121] and plasma } \\
\text { [60] VEGF }\end{array}$ \\
\hline \multirow[t]{2}{*}{ Decreased $\mathrm{O}_{2}$ consumption } & $\begin{array}{l}\text { Metabolic re- } \\
\text { programming }\end{array}$ & $\begin{array}{l}\text { Increased expression of } L D H A \text { and } \\
\text { GLUT1 [63], increased CSF lactate } \\
\text { [69] }\end{array}$ \\
\hline & $\begin{array}{l}\text { Decreased citric acid } \\
\text { cycle flux }\end{array}$ & $\begin{array}{l}\text { Decreased citric acid cycle } \\
\text { metabolites in PBMC [65] }\end{array}$ \\
\hline \multirow[t]{4}{*}{$\begin{array}{l}\text { Alterations in mitochondrial } \\
\text { function and biogenesis }\end{array}$} & $\begin{array}{l}\text { Decreased } \\
\text { mitochondrial mass }\end{array}$ & $\begin{array}{l}\text { Decreased expression of } \\
\text { mitochondrial biogenesis genes [93] }\end{array}$ \\
\hline & Disturbed dynamics & $\begin{array}{l}\text { Increased fragmentation and impaired } \\
\text { mitophagy [91] }\end{array}$ \\
\hline & $\begin{array}{l}\text { Remodeling ETC } \\
\text { complexes }\end{array}$ & $\begin{array}{l}\text { Decreased complex I and IV activity } \\
{[76]}\end{array}$ \\
\hline & $\begin{array}{l}\text { Decreased ATP } \\
\text { demand }\end{array}$ & $\begin{array}{l}\text { Decreased enzymatic activity [81] } \\
\text { and gene expression [83] of NA/K } \\
\text { ATPase }\end{array}$ \\
\hline
\end{tabular}

ATP, adenosine triphosphate; EPO, erythropoiesis; ETC, electron transport chain; GLUT1, Glucose transporter 1; LDHA, lactate dehydrogenase A; MDD, major depressive disorder; PBMC, peripheral blood mononuclear cells; VEGF, vascular endothelial growth factor. 


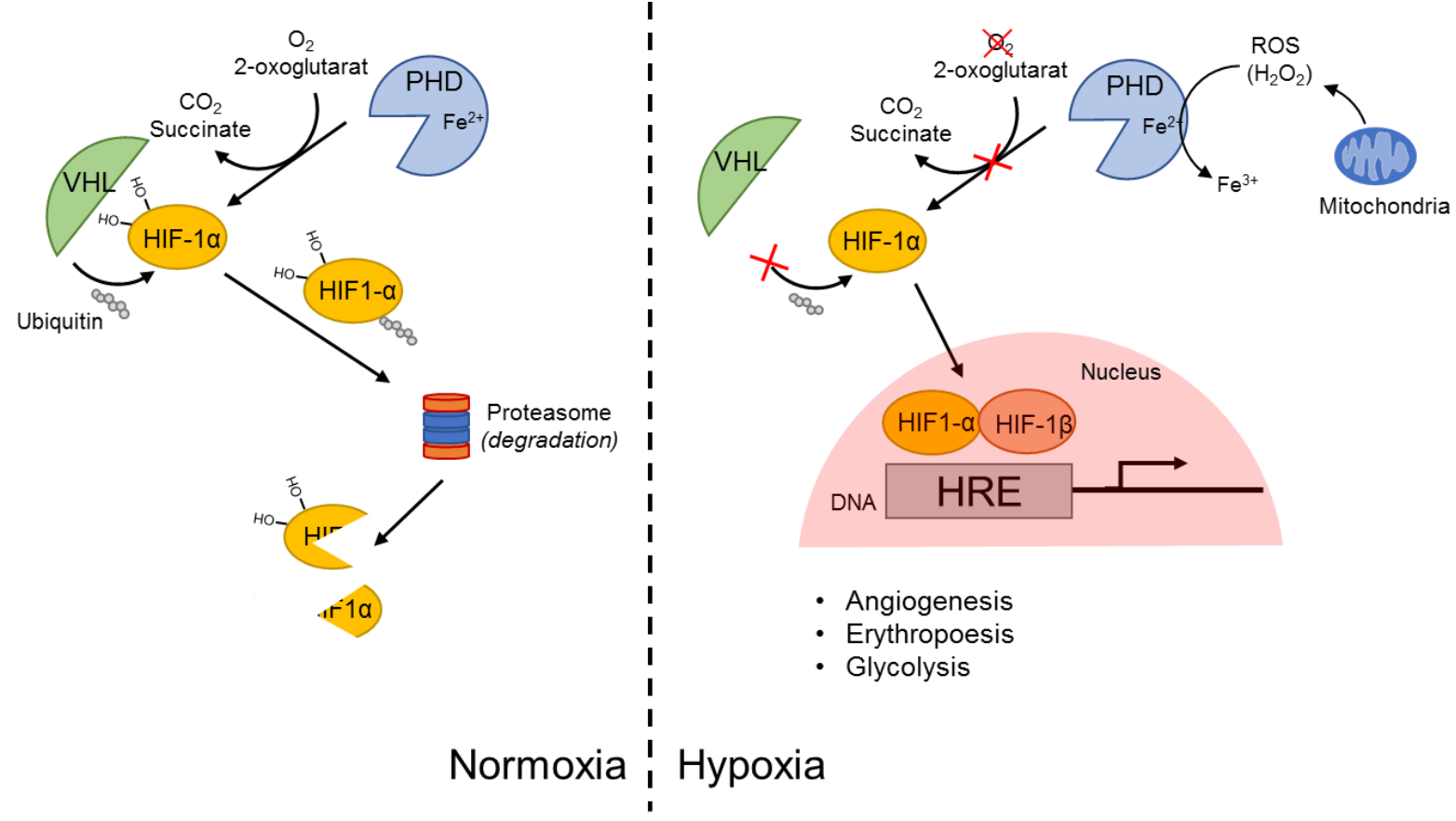

Figure 1. Hypoxia-inducible factor 1 regulates cellular response to hypoxia. Under normal oxygen $\left(\mathrm{O}_{2}\right)$ concentrations, Hypoxia-inducible factor 1-alpha (HIF-1 $\alpha$ ) subunit is hydroxylated by prolyl hydroxylase domain protein (PHD). Hydroxyl groups signal binding to Von-Hippel-Lindau protein (VHL), which mediates ubiquitination and the subsequent proteasomal degradation of HIF-1 $\alpha$. Low $\mathrm{O}_{2}$ level and increased reactive oxygen species (ROS) inhibit PHD activity and stabilize HIF-1 $\alpha$. HIF-1 heterodimer (HIF-1 $\alpha /$ HIF $1-\beta)$ binds to HIF-1 responsive elements (HRE) and regulates transcription of genes involved in angiogenesis, erythropoiesis, and glycolysis. 


\section{Chronic stress}

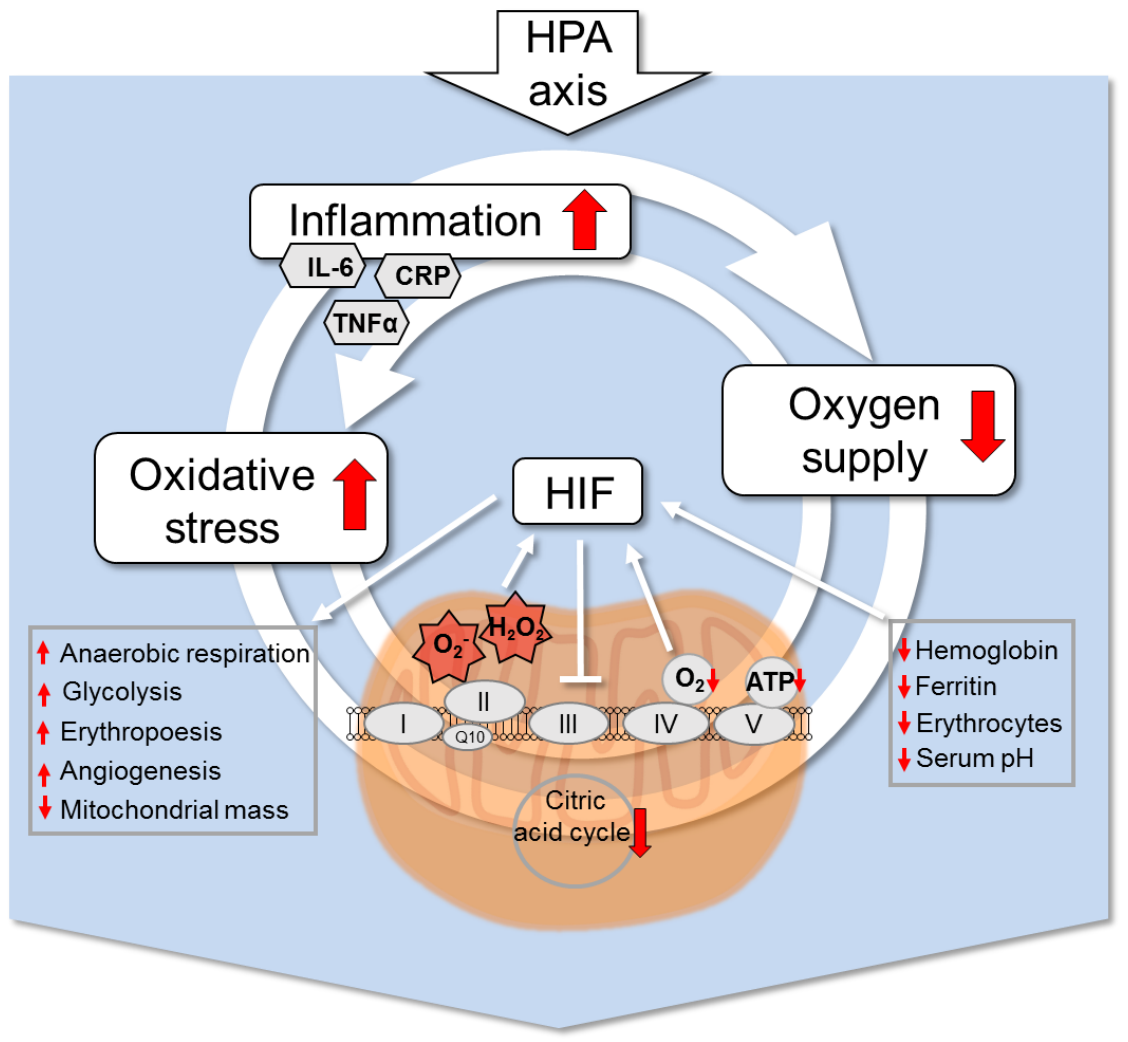

Figure 2. Proposed model of major depressive disorder as a low-grade hypoxic condition.

Chronic stress leads to an induction of inflammation and oxidative stress via the hypothalamicpituitary-adrenal (HPA) axis. Inflammation and oxidative stress disturb oxygen $\left(\mathrm{O}_{2}\right)$ supply elements. Decreased $\mathrm{O}_{2}$ supply affects mitochondrial function and reactive oxygen species (ROS) production, which induces Hypoxia Inducible Factor (HIF) response. Consequently, metabolic reprogramming shifts oxidative phosphorylation towards anaerobic respiration and glycolysis. Additionally, mitochondria are restructured to optimize $\mathrm{O}_{2}$ consumption and adenosine triphosphate (ATP) production as well as reduce ROS production. Despite these adaptations, ATP production is decreased leading to energy shortage. 